\title{
Effect of Used Lubricating Oil Contaminated Soil on Seed Germination and Early Growth Performance of Wild -Type Legume, Crotalaria retusa $\mathbf{L}$.
}

\author{
Walakulu Gamage S.S. ${ }^{1}$, Masakorala K. ${ }^{1 *}$, Brown M.T. ${ }^{2}$, Widana Gamage S.M.K. ${ }^{1}$ \\ ${ }^{1}$ Department of Botany, Faculty of Science, University of Ruhuna, Sri Lanka \\ ${ }^{2}$ School of Biological \& Marine Sciences, Plymouth University, United Kingdom \\ *masakorala12@yahoo.com
}

\begin{abstract}
Contamination of soil due to used lubricating oil (ULO) has become a common environmental issue, especially in major cities worldwide. This may affect negatively on overall soil quality and may pose a risk to biota. Phytoremediation is a novel green technological approach, which uses plants to remove organic and inorganic pollutants from contaminated soil, air and water and can be usefully used to clean up ULO contaminated soil. Screening of plant species with tolerance to ULO contamination is the most critical initial step in phytoremediation. The aim of the present study is to evaluate tolerance of Crotalaria retusa L. to ULO-contaminated soil. Germination of $C$. retusa seeds in soils with $1-5 \% \mathrm{w} / \mathrm{w}$ ULO contamination levels was tested according to the ISO method, with five replicates per treatment and ten seeds per replicate. Percentage inhibition of seed germination, root growth and biomass were measured at 48 and 72 hours of incubation. Results showed $100 \%$ seed germination in the control (uncontaminated soil) and all treatments indicating high tolerance of tested seeds to germinate in ULO-contaminated soil. However, there was a significant $(\mathrm{p}<0.05)$ reduction in root length of seedlings in all treatments above $3 \% \mathrm{w} / \mathrm{w}$ ULO. Therefore, a further pot experiment was carried out using ULO contamination levels of $0.5 \%$, $1 \%, 1.5 \%, 2 \%, 2.5 \%$ and $3 \% \mathrm{w} / \mathrm{w}$ ULO. A fully randomized block design (RBD) was employed with 4 replicates per treatment and control. Percentage biodegradation of ULO and shoot height were measured monthly and at the end of a three month exposure chlorophyll a, $\mathrm{b}$, total chlorophyll content, shoot height, root length, shoot system biomass and root system biomass were all measured. Results indicated time-dependent increases in percentage biodegradation of different treatments. At three months, percentage biodegradation was $52.2 \%, 43.8 \%, 35.6 \%, 32.2 \%, 25.2 \%$ and $22.0 \%$ for the $0.5-3.0 \% \mathrm{w} / \mathrm{w}$ ULO treatments, respectively. A decrease in growth parameters was observed with an increase in ULO contamination levels. However, the calculated $\mathrm{IC}_{50}$ values inferred that the substantial negative effects resulted only on plants grown in soil with contamination levels greater than $2 \% \mathrm{w} / \mathrm{w}$. There were no significant differences in chlorophyll contents of seedlings under any treatments. Therefore, from the present study we can conclude that $C$. retusa is able to grow in soils contaminated with ULO up to a level of $2 \% \mathrm{w} / \mathrm{w}$ without showing any negative effects. This result highlights the potential of $C$. retusa for the phytoremediation of ULO contaminated soil.
\end{abstract}

Keywords: Crotalaria retusa, Phytoremediation, Used lubricant oil

Acknowledgements: National Research Council, Sri Lanka (Grant No. 16-144) for financial assistance

Proceedings of the $22^{\text {nd }}$ International Forestry and Environment Symposium 2017 of the Department of Forestry and Environmental Science, University of Sri Jayewardenepura, Sri Lanka 